\title{
"Não é competência do professor ser sexólogo" O debate público sobre gênero e sexualidade no Plano Nacional de Educação
}

\author{
"Being a sexologist is not a teacher's competence" \\ The public debate on gender and sexuality in the National Education Plan \\ Elaine Reis Brandão \\ (1) Rebecca Faray Ferreira Lopes
}

\begin{abstract}
Resumo: O trabalho discute as premissas que regem o debate público na sociedade brasileira sobre a inclusão dos conteúdos relativos ao gênero e à sexualidade no Plano Nacional de Educação. Trata-se de pesquisa socioantropológica documental, com documentos extraídos de fontes públicas na internet, no período 2011-2017, compreendendo órgãos governamentais, organizações não governamentais, portais de notícias diversos. A perspectiva de construção social do gênero e da sexualidade é questionada por ser considerada disruptiva à família para certos segmentos religiosos e políticos, não devendo ser tratada na escola. Outra visão se apoia nas discriminações e violências sofridas por estudantes devido ao estigma e desigualdade de gênero persistente nos espaços escolares. Assim, tais conteúdos ajudariam no processo educativo de convivência com a diversidade sexual, de gênero, e racial. Nesse debate, a dimensão sociocultural e política do gênero e da sexualidade se afirmam. Aspectos intervenientes na aprovação das políticas públicas sinalizam dificuldades para se garantir o Estado laico, denotando o que Carrara designa como "nova geografia do mal e do perigo sexual" ao discutir as politicas sexuais e seus peculiares estilos de regulação moral.
\end{abstract}

Palavras-chave: Gênero. Sexualidade. Educação. Política sexual. Moralidade.

Abstract: The article aims to systematize and discuss the premises conducting the recent public debate in the Brazilian society regarding the inclusion of gender and sexuality-related contents in the National Education Plan. It is a documental socioanthropological research with documents extracted from public internet sources

* Doutora em Saúde Coletiva pela Universidade do Estado do Rio de Janeiro (Uerj, Rio de Janeiro, RJ, Brasil), professora associada do Instituto de Estudos em Saúde Coletiva, da Universidade Federal do Rio de Janeiro (UFRJ), igualmente no Rio de Janeiro < brandao@ iesc.ufrj.br>.

**Graduada em Saúde Coletiva pela Universidade Federal do Rio de Janeiro (UFRJ, Rio de Janeiro, RJ, Brasil), mestranda em Saúde Pública na Escola Nacional de Saúde Pública, da Fundação Oswaldo Cruz (Fiocruz), igualmente no Rio de Janeiro <rebecca.faray@gmail.com>.

Civitas, Porto Alegre, v. 18 , n. 1, p. 100-123, jan.-abr. 2018

Exceto onde especificado diferentemente, a matéria publicada neste periódico

é licenciada sob forma de uma licença

Creative Commons Attribution-NonCommercial-NoDerivatives 4.0 International License 
between 2011-2017, comprising government bodies, non-governmental organizations, and several news sites. The social construction of gender and sexuality perspective is questioned for being disruptive to the family for certain religious and political segments, being its approach in the school considered inappropriate. Another view is based on the discrimination and violence suffered by the students, due to the persisting stigma and gender inequality in the school settings. Thus, such contents would aid in the educational process of coexistence with sexual, gender and racial diversity. In this debate, sociocultural and political dimension of gender and sexuality are affirmed. Intervenient aspects in the approval of public policies indicate difficulties to guarantee the secular State, denoting what Carrara refers as "new geography of evil and sexual danger" when discussing sexual policies and their peculiar styles of moral regulation.

Keywords: Gender. Sexuality. Education. Sexual Politics. Morality.

\section{Introdução ${ }^{1}$}

A divulgação pela mídia, no Brasil, das polêmicas envolvendo a aprovação do Plano Nacional de Educação (PNE) e de planos estaduais e municipais subsequentes foi bastante expressiva nos últimos anos. Devido à inclusão de categorias sociais no art. 2, inciso III na terceira diretriz, em que se determina: "superação das desigualdades educacionais, com ênfase na promoção da igualdade racial, regional, de gênero e de orientação sexual" (Brasil, 2012, p. 1), surgiram vários entraves a sua aprovação.

O art. 214 da Constituição Federal de 1988 estabelece que o PNE seja decenal, articulado ao Sistema Nacional de Educação, para estipular, dentre outras incumbências, as metas e diretrizes, de modo a ser implementado "para assegurar a manutenção e desenvolvimento do ensino em seus diversos níveis, etapas e modalidades por meio de ações integradas dos poderes públicos das diferentes esferas federativas" (Brasil, 1988). O primeiro PNE foi sancionado para vigorar no período de 2001-2010, na gestão do então presidente Fernando Henrique Cardoso.

A menção às categorias de "gênero" e "orientação sexual" no texto do segundo PNE (projeto de lei no 8.035/2010) provocou debates incisivos na sociedade brasileira, culminando com o retorno do texto final à Câmara dos Deputados, em 2014. Alguns segmentos sociais e políticos discordaram veementemente que os temas da sexualidade e do gênero devam ser tratados na esfera pública, em espaços como a escola. Consideram-nos assuntos de

\footnotetext{
${ }^{1} \mathrm{O}$ artigo se apoia na monografia de conclusão de curso de graduação em saúde coletiva de Rebecca Faray Ferreira Lopes, orientada por Elaine Reis Brandão, no Instituto de Estudos em Saúde Coletiva, da Universidade Federal do Rio de Janeiro, defendida em março de 2017. A elaboração deste texto foi feita por Elaine R. Brandão, em diálogo com Rebecca F. F. Lopes.
} 
ordem privada, restritos ao ambiente familiar. Por não concordarem com a inclusão do que designam como "ideologia de gênero", expressão discutida adiante, fizeram forte oposição ao mesmo, mobilizando esforços para barrar quaisquer avanços nessa direção. As resistências surgidas contribuíram para um considerável atraso na aprovação do PNE, ocorrendo somente no ano de 2014 - quando deveria ter sido aprovado em 2010 - sem mencionar os termos gênero e orientação sexual. $\mathrm{O}$ texto final do inciso citado alterou-se para "superação das desigualdades educacionais, com ênfase na promoção da cidadania e na erradicação de todas as formas de discriminação" (Brasil, 2014 p. 1).

A relevância deste debate está relacionada à luta social para efetivação de direitos garantidos na Constituição de 1988. Em 2014, com a proximidade da eleição presidencial no país, o cenário político brasileiro sofreu uma acirrada disputa que culminou com uma fratura da sociedade civil em lados opostos. De um lado, alguns partidos de esquerda e determinados movimentos sociais buscando avanços nos direitos sociais conquistados, que ainda precisam ser consolidados. Do outro, partidos e forças conservadoras de direita interessados em retroceder as conquistas sociais em diversos campos como saúde, educação, direitos humanos, proteção ao meio ambiente, etc. A eleição deste mesmo ano para o Congresso Nacional resultou em maior número de representantes políticos de segmentos conservadores e/ou religiosos, trazendo ameaças aos direitos e legislações conquistados a partir do marco democrático de 1988.

O atual cenário de retrocesso político instaurado no Brasil coloca em risco vários avanços sociais no campo da afirmação dos direitos das mulheres e da população de lésbicas, gays, bissexuais, travestis e transexuais/transgêneros (LGBT), obtidos nas últimas décadas, aprofundando sobremaneira as desigualdades de gênero.

Não incentivar a discussão de gênero e sexualidade na escola contribui para a persistência das desigualdades e discriminações sociais, bem como para expressões de violência, no espaço escolar ou em outros ambientes sociais. $\mathrm{O}$ debate sobre gênero e sexualidade na escola pode diminuir o machismo e a misoginia, conduzir à promoção da igualdade de gênero e da diversidade sexual, por meio do aprendizado do convívio com diferenças socioculturais. Assim, evitam-se situações de sofrimento, adoecimento e abandono escolar por razões que não competem somente a adolescentes.

Discutir tal problemática decerto ajudará a fortalecer a luta pela afirmação dos direitos humanos no país. O poder de alcance do PNE em todo estado brasileiro, as leis que o sustentam tornam-no capaz de dar voz às 
agendas de fortalecimento da cidadania nas escolas de todo o país (Carreira et al., 2016).

Assim, o objetivo do artigo é discutir as premissas que regem o debate público na sociedade brasileira sobre a inclusão dos conteúdos relativos ao gênero e à sexualidade no PNE. Busca-se estabelecer uma relação entre tal panorama político e o que o antropólogo Sérgio Carrara (2015) designa como "nova geografia do mal e do perigo sexual", ao discutir as politicas sexuais e seus peculiares estilos de regulação moral na contemporaneidade.

\section{Procedimentos metodológicos}

Trata-se de pesquisa socioantropológica, de natureza documental (Sá-Silva, Almeida, Guindani, 2009; Cellard, 2008) relativa ao debate público sobre inclusão dos conteúdos de gênero e sexualidade no PNE, no período de 2011-2017. Os documentos coletados são oriundos de fontes disponibilizadas na internet, através de sites de notícias, blogs de opinião, órgãos governamentais e organizações não governamentais (ONGs), de acesso público, selecionados de maneira a abarcar as diferentes perspectivas da discussão.

A busca pelo material empírico ocorreu entre agosto de 2016 a agosto de 2017, orientada pelos descritores "PNE", "gênero" e "sexualidade" em conjunto, a partir do site de buscas Google. Em um primeiro momento, foram identificados 55 sites ou blogs como fontes para a pesquisa, tendo sido reunidos 70 documentos, os quais obedeciam ao critério de apresentar um conteúdo temático que abordasse o debate mencionado como objeto de estudo. Para esse artigo, por razões de síntese da discussão, foram incluídos 46 documentos, de fontes como portais de notícias (públicos ou privados), religiosos e ONGs (listados em anexo). Os documentos foram classificados em notícias (17); entrevistas (5); artigos de opinião (12) e notas públicas (12).

A análise do material evidenciou uma categoria chave, recorrente nos documentos - "ideologia de gênero", discutida à frente. Duas premissas ou argumentos foram depreendidos da análise do material empírico, os quais orientam a discussão dos dados. Uma posição deteve-se na importância de integrar o debate sobre gênero e sexualidade na socialização escolar e a segunda sustenta que a discussão sobre gênero e sexualidade ameaça a ordem familiar.

Em seguida, apresenta-se tais argumentos em jogo no debate público e os interlocutores que protagonizaram as disputas e conflitos políticos em torno da aprovação do PNE. Configura-se assim o cenário de forças sociais e políticas que possibilitam melhor compreensão dos atores sociais e de suas práticas discursivas. 


\section{Gênero e sexualidade nas políticas públicas de educaçã $0^{2}$}

A Constituição brasileira garante a educação como direito básico, assim como a Lei das Diretrizes e Bases da Educação Nacional (Brasil, 1996) e o Estatuto da Criança e do Adolescente (Brasil, 1990), que ratificam em sua base legal iguais oportunidades de acesso escolar, liberdade de pensamento e a diversidade.

A fim de favorecer a melhoria do ensino público no Brasil, após árduo processo político de negociação durante a redemocratização do país, e promover a inclusão dos conteúdos de gênero e sexualidade no currículo escolar, o governo brasileiro criou em 1996 os Parâmetros Curriculares Nacionais (PCN) (Brasil, 1997), que continham diretrizes para se debater a educação em sexualidade na escola, antes de responsabilidade estrita das famílias.

Vianna e Unbehaum (2004) fazem uma exaustiva análise sobre o gênero nas políticas de educação e apontam uma inflexão a partir da elaboração dos PCN para o ensino fundamental, nos quais o gênero passa a ser desvelado e abordado de modo mais direto, ao contrário dos documentos anteriores, onde ele permanecia velado e subentendido na expressão mais ampla de "direitos".

Os PCN discorrem sobre a educação sexual ser tratada de forma transversal, trabalhada em todas as disciplinas e pelo conjunto de docentes, a fim de se problematizar o aumento do número de gravidez na adolescência e a contaminação pelo HIV. Há muitos desafios em se trabalhar a transversalidade dos conteúdos de gênero e sexualidade nas escolas, pois ainda persiste uma ênfase nos aspectos biológicos, no ensino do corpo humano pela disciplina de ciências, interpretando o corpo somente como um conjunto de peças e aparelhos reprodutores (Carrara et al., 2009). A sexualidade continua sendo abordada na perspectiva do risco e das doenças, para prevenir os problemas de saúde como forma de controle dos agravos (Palma et al., 2015).

Boa parte das políticas educacionais que buscam trabalhar gênero e sexualidade deslizam em concepções normativas, preventivistas e biologizantes (Junqueira, 2010; Seffner, 2011; 2013; Nardi e Quartiero, 2011), devido à dificuldade de se retirar os temas da sexualidade e do gênero do contexto da "natureza humana" e transportá-los para o âmbito da cultura.

\footnotetext{
${ }^{2}$ Não se tem a intenção de elaborar um inventário histórico sobre todas as iniciativas que contemplam as temáticas de gênero e sexualidade no âmbito escolar, nem um escrutínio minucioso destas políticas. Busca-se somente problematizar alguns aspectos desta inclusão e suas dificuldades no cotidiano escolar.
} 
Estudos recentes realizados no ambiente escolar com docentes ou estudantes (Gesser, Oltramari, Panisson, 2015; Longaray e Ribeiro, 2015; Mariano e Altmann, 2016) ou sobre materiais didáticos (Oliveira e Diniz, 2014) apontam limitações nas abordagens dos temas de sexualidade e gênero, subordinando-os a uma visão essencialista, normativa e determinista. Em análise sobre a incorporação dos temas da diversidade sexual e do gênero nas políticas públicas de educação, Vianna (2015) ressalta que docentes dos níveis fundamental II e médio da rede pública estadual de ensino da cidade de São Paulo, por ela entrevistado/as, não conseguiram alterar suas práticas pedagógicas após terem passado por formação específica sobre tais temas. A autora explora as tensões entre desigualdades sociais e de gênero na relação entre estado e movimentos sociais (LGBT), apontando dificuldades estruturais para transformação das práticas educativas: "as ações do Estado parecem querer valorizar a diversidade sexual sem considerar as relações de poder que a heteronormatividade chancela" (Vianna, 2015, p. 802).

Carrara et al. (2009) observam que na abordagem da sexualidade na escola, as crianças não são reconhecidas como sujeitos de direitos. Essa interpretação leva pessoas adultas a condenarem a temática na escola por ser assunto a ser tratado na intimidade da família. Como ressaltam "é preciso questionar esta visão, e refletir sobre como o silêncio em relação a situações de discriminação por preconceito e violência de gênero contribuem para a reprodução de uma ordem desigual e injusta" (Carrara et al., 2009, p. 141).

A escola representa um espaço relevante na formação de indivíduos, fomentando modos de socialização que tendem a reproduzir atitudes discriminatórias e relações de poder em favor da heterossexualidade como norma social. Daí a centralidade desta relação docente-estudante para problematização e desconstrução de estereótipos sociais e construção coletiva de novos modos de respeito ao outro.

\section{O debate no Congresso Nacional}

O debate sobre o PNE colocou em cena interlocutores em absoluta dissonância sobre a centralidade da educação pública no aprendizado dos conteúdos de sexualidade e gênero desde a infância e adolescência.

A chamada "ideologia de gênero" terminou por catalisar os embates e disputas entre segmentos políticos opostos, ecoando no Brasil uma tensão também presente em outros contextos latino-americanos (Clam, 2016a; Wilkinson, 2017; Reis e Eggert, 2017). Registrou-se um acirramento do conservadorismo religioso (Facchini, Sívori, 2017) em âmbito global e latino- 
americano, que repercute de diversas formas, no caso do Brasil, com projetos de lei em tramitação para barrar conquistas sociais, como o aborto permitido por lei, o uso da contracepção de emergência, entre outros.

Destacam-se inicialmente os títulos dos textos publicados na mídia, cuja postura tendenciosa gera desinformação e pânico moral. ${ }^{3}$ Longe de conduzir o leitor a compreender o que está em discussão, o público é condicionado de antemão pelo tom alarmista dos destaques criando incertezas e tensões. $\mathrm{O}$ leitor não é devidamente informado para que seja possível tirar suas próprias conclusões sobre o tema em pauta.

Alguns exemplos podem ser citados: "Projetos contra a família: PNE e a ameaça de gênero" (Portal da Família, 2013); "Perigo: governo do PT planeja introduzir a ideologia de gênero nas escolas através do PNE" (O Povo, 2013); "Professor que discutir gênero nas escolas poderá ser preso" (Portal Aprendiz, 2015); "Exclusão de gênero do PNE é retrocesso, diz educador" (IG, 2015); "Católicos e evangélicos em cruzada contra a palavra gênero na educação" (El País, 2015); "Polêmica sobre questão de gênero predomina em reunião sobre PNE" (Gazeta do Povo, 2014).

O blog O Ancoradouro (O Povo, 2013) noticiou a proposta de lei do PNE como um documento do "governo do PT". O título equivocado gera impacto negativo, principalmente em segmentos sociais cuja rejeição ao Partido dos Trabalhadores (PT) vem se ampliando ao longo dos anos.

No tocante à tramitação havida no Congresso Nacional, após a inclusão de inúmeras emendas anexadas por outros deputados no período de 2011 a 2012, o deputado Ângelo Vanhoni (PT-PR) conseguiu levar ao Senado Federal em dezembro de 2012 a proposta de lei do PNE, aprovada na Câmara dos Deputados em outubro do mesmo ano. O relator deveria ser o senador José Pimentel, também do PT, porém houve mudanças e a relatoria do PNE foi atribuída ao senador Álvaro Dias (PSDB-PR). Este, por sua vez, modificou o texto base, retirando o trecho em que estavam mencionadas as categorias "gênero" e "orientação sexual". Contudo, ao retornar à Câmara dos Deputados, o relator original do texto rejeitou as alterações advindas do Senado.

O Portal da Família (2013) noticiou que caso a lei do PNE fosse aprovada, a "ideologia de gênero" seria obrigatória a estudantes, garantindo a distribuição de "kits gays" nas escolas e a "educação sexual compulsória"

\footnotetext{
${ }^{3}$ O conceito de pânico moral foi utilizado pelo sociólogo Stanley Cohen em 1972 quando "uma condição, episódio, pessoa ou grupo de pessoas emerge para ser definido como uma ameaça aos valores e interesses sociais" (Heilborn, Brandão, Cabral, 2007).

${ }^{4} \mathrm{Em}$ alusão à iniciativa governamental de distribuir o material didático do Programa Brasil Sem Homofobia, concebido pela Secadi/MEC, cuja distribuição foi suspensa em 2011.
} 
para "demolir" a família "natural". Assim, conclamou os "católicos, padres, espíritas e toda a sociedade a repudiar o PNE proposto pela certeza que o PT tentará 'empurrar' a votação a todo custo com ajuda de 'grupos internacionais' para instaurar a 'ideologia de gênero' na educação brasileira”. A divulgação da votação nas redes sociais foi sugerida com vista à mobilização social para retirada da "ideologia de gênero" do PNE.

Padre Paulo Ricardo (2014), da arquidiocese de Cuiabá, Mato Grosso, apresentador do programa de televisão da comunidade Canção Nova, alertou que de forma "urgente" o Congresso poderia aprovar a "ideologia de gênero", conclamando seus leitores a enviarem cartas aos deputados para barrar a redação original do PL. Em texto na Gazeta do Povo (2014), ressaltam-se as faixas estampadas por religiosos no plenário da Câmara: "abaixo à ideologia de gênero".

O deputado Jair Bolsonaro, na ocasião do Partido Progressista, do Rio de Janeiro, designou o PNE como "Plano Nacional da Vergonha" e aproveitou sua votação para criticar o Plano Nacional de Promoção da Cidadania e Direitos Humanos de Lésbicas, Gays, Bissexuais, Travestis e Transexuais, implementado pelo governo federal, a partir de 2009. Como enfatizou um dos principais interlocutores da oposição à inclusão das temáticas de gênero e sexualidade na escola: "todo esse material vai para a garotada a partir dos seis anos de idade ensinando-as a serem homossexuais" (Revolta Brasil, 2014).

Cleomar Manhas, doutora em educação pela PUC-SP, no blog Outras Palavras (2014), comentou as dificuldades na votação do PNE devido aos dissensos entre entidades educacionais e religiosas (evangélicas neopentecostais, católicas conservadoras, que se intitulam "pró-vida"), com lugar às "manifestações grosseiras e pouco democráticas".

A autora mencionou uma pesquisa da Unicef, realizada em 2010, com estudantes do ensino fundamental no Brasil, cujos principais motivos de abandono escolar foram as desigualdades racial, de gênero, regional, de renda, ou ainda por preconceitos devido à orientação sexual e falta de acessibilidade para pessoas com deficiência. Na mesma direção, o deputado Jean Wyllys, do Partido Socialismo e Liberdade, do Rio de Janeiro (Psol-RJ), enfatizou a necessidade de políticas públicas que possam promover a superação das desigualdades de gênero e o diálogo sobre sexualidade, para se evitar o bullying sofrido na escola (Educar para Crescer, 2014).

São vários os documentos que mencionam a "bancada cristã", a "cruzada religiosa", o "lobby religioso" ou o "lobby conservador" ao designarem as forças políticas de oposição à inclusão das temáticas relativas à defesa e afirmação dos direitos humanos nos documentos oficiais (De Olho nos Planos, 2014; El País, 2015; Pragmatismo Político, 2015). O grupo reúne parlamentares dos partidos 
Social Democracia Brasileira (PSDB), Movimento Democrático Brasileiro (PMDB), Social Cristão (PSC), como Marcos Feliciano (PSC-SP), Jair Bolsonaro (PSC-RJ), Pastor Eurico, do Partido Humanista da Solidariedade (PHS-PE), entre outros. O deputado federal Eduardo Cunha (PMDB-RJ), na época presidente da Câmara dos Deputados, aliado dos "deputados cristãos" favoreceu sobremaneira os protestos contra o PNE no plenário da Câmara (El País, 2015).

Após quatro anos em debate, o PNE foi sancionado com o trecho "polêmico" modificado, sinalizando uma vitória das forças políticas conservadoras. O apelo que realçava a vulnerabilidade das crianças em face do poder (subversivo) do estado ecoou mais forte. Assim como no passado, na conjuntura política atual, os conceitos de gênero e sexualidade são sempre marcados por impedimentos políticos contrários às transformações sociais (Louro, 1997). Vejamos, a seguir, a análise mais detida das duas premissas em disputa neste debate.

\section{Compromisso com a democracia}

O Brasil é signatário de vários tratados e conferências que garantem a promoção dos direitos humanos e o compromisso com a democracia. Durante o debate sobre o PNE, vários especialistas em educação, ciências sociais, representantes de ONG e de outros movimentos sociais se manifestaram na direção de assegurar a pluralidade e a diversidade étnico-racial, de gênero e sexual no ensino público (ABA, 2015; ABCP, 2015; Anped, 2016; De Olho nos Planos, 2015; Geledés, 2015; Congresso em Foco 2015a; Clam, 2016b; ONU Mulheres, 2017). Essa vertente corrobora a premissa de que gênero e sexualidade são necessários e integram de modo indispensável a socialização e o aprendizado escolares.

Consultado como pesquisador da área (Geledés, 2011), M. Daniliauskas, então doutorando em educação na Universidade de São Paulo (USP), afirmou que o projeto de lei apresentado em 2010 necessitava aprofundar a abordagem referente à sexualidade, propondo medidas referentes à exclusão social causada pela discriminação como o bullying em estudantes com suspeita de serem homossexuais. Conforme o pesquisador, docentes também são vítimas de homofobia e de atitudes discriminatórias, tendo a todo instante seu trabalho e sua sexualidade desvalorizados. Para o educador, o papel da escola tem como princípio básico o desenvolvimento da cidadania e o "pleno desenvolvimento da pessoa humana", de modo que todos aprendam a lidar com as diferenças. Por isso, para ele, é necessário trabalhar a discriminação sexual, o racismo dentro da escola (Geledés, 2011). 
Em carta aberta de entidades educacionais, divulgada e assinada pelo Geledés, deixou-se claro por quais motivos se devia apoiar o relator do PNE:

O PNE não pode se eximir de planificar uma educação que respeite integralmente todos os cidadãos e cidadãs em território nacional, fazendo das políticas educacionais um instrumento fundamental de combate aos preconceitos e à violência contra a mulher, contra os negros e as negras e contra a comunidade LGBT (Geledés, 2014).

No portal De Olho nos Planos (2014), Vianna (USP) comentou o quanto se podia ganhar trabalhando as questões de gênero nas escolas. Afirma que as diferenças contribuem ensinando o quanto se deve viver e aprender com pessoas diferentes, porém sem corroborar com as desigualdades. Outro argumento da pesquisadora diz respeito à função social desempenhada pela escola enquanto instituição. Ao ter contato com formas de vivências distintas, muitos aprendizados podem condicionar a busca por significados de comportamentos presentes no ambiente familiar, como a violência doméstica.

Seffner (2011) também ressalta que se uma política pública avança nas questões de gênero e sexualidade, tal articulação favorece quem tem sua voz silenciada por desigualdades e discriminações sofridas dentro da escola ou no ambiente familiar. Seja em relação ao uso de roupa curta das meninas ou comportamentos sentimentais ou "afeminados" dos meninos que os fazem sofrer constrangimentos pelos colegas por não ajustamento à heterossexualidade hegemônica, a família intervém exercendo influência nas decisões dos professores e diretores.

A escola, ao deixar influenciar-se pelo conservadorismo e valores familiares, ao permitir que seu espaço seja confundido com o espaço privado, acaba dificultando a prática formadora da igualdade entre indivíduos, das relações sociais que deveriam promover a equidade de gênero e de orientação sexual na instituição pública (Seffner, 2011).

Toni Reis, secretário da Associação Brasileira de Lésbicas, Gays, Bissexuais, Travestis e Transexuais (ABGLT), ressaltou em sua coluna, a história dos direitos humanos com uma influência importante para políticas públicas brasileiras. Através dos compromissos firmados desde as Conferências da Organização das Nações Unidas (ONU), focalizaram-se ações que pudessem proporcionar avanços nas políticas brasileiras. Segundo Reis, a versão apresentada ao Congresso evidenciou as desigualdades persistentes no país que deveriam ser "priorizadas na educação nos próximos dez anos, com vistas à sua erradicação: a desigualdade racial, regional, de gênero e de orientação sexual" (Congresso em Foco, 2015b). 
Em outra entrevista, ele pontuou: "O que se pretende com a inclusão do tema da igualdade de gênero nos Planos de Educação é diminuir as desigualdades entre os gêneros, o machismo e a inferiorização das meninas e mulheres". Reis lembrou que nosso país tem como sua maior diretriz a Constituição de 1988 "cujos princípios incluem a igualdade de condições para acesso e permanência na escola, o respeito à liberdade, o apreço à tolerância e o conhecimento e exercício da cidadania" (EBC, 2015a).

Apesar do marco democrático, há um número notável de violações de direitos das mulheres, das pessoas LGBT, incluindo homicídios motivados por ódio. As atitudes discriminatórias estão sempre relacionadas ao gênero e à orientação sexual: "Eis a importância de educar para o respeito à igualdade de gênero, visando modificar para melhorar esses quadros na sociedade como um todo e também nos estabelecimentos educacionais" (De Olho nos Planos, 2015).

A crise aberta pela aprovação do PNE no Brasil motivou o posicionamento de várias entidades nacionais e internacionais em apoio ao ensino com respeito à diversidade de gênero e sexual. A Organização das Nações Unidas para a Educação, a Ciência e a Cultura (Unesco) defende uma educação equitativa debatendo gênero e sexualidade nas escolas. Para a Unesco, as legislações brasileiras deveriam abarcar tais perspectivas para que se formem cidadãs e cidadãos entendedores/as das mais variadas dimensões sociais existentes.

Quando mulheres e homens são educados com equidade nas escolas, todos têm seus direitos garantidos nos aprendizados e nas relações construídas: "a intenção é que as escolas ensinem aos estudantes que todas as pessoas são iguais, independentemente da identidade de gênero, e que existem diversas orientações sexuais, que devem ser respeitadas" (Agência Brasil, 2016).

Em nota pública, também a ONU Mulheres (2016) declarou que a educação brasileira deveria ser pautada em questões de gênero e garantida em políticas públicas educacionais.

A ONU Mulheres Brasil expressa profunda preocupação com as propostas de retirada da educação para a igualdade de gênero das escolas e demais instituições de ensino no Brasil. Tais iniciativas visam alterar marcos legais e políticos, leis e tratados internacionais, fundamentais para o desenvolvimento da cidadania no Brasil e o enfrentamento de desigualdades estruturais de gênero, raça, etnia e orientação sexual.

A nota ressaltou que autoridades públicas deveriam resguardar a proteção dos direitos humanos da população para preservar os valores de liberdade 
e igualdade: "Esses são valores decisivos para uma sociedade plural e sem discriminações, preconceitos e violências de qualquer natureza".

O Conselho Nacional da Educação (2015) e a Secretaria de Educação Continuada, Alfabetização, Diversidade e Inclusão igualmente emitiram notas à sociedade. $\mathrm{O}$ documento mencionou a história dos conceitos de gênero $\mathrm{e}$ orientação sexual como construções sociais, cuja pretensão no ambiente educacional é demonstrar a representação das diversas práticas de gênero e de orientação sexual presentes nos espaços sociais. Por ser um espaço de ensinamento de comportamentos e currículos escolares heteronormativos, busca-se com a nova linguagem reconhecer a "diversidade de desejos e de relações sexuais e afetivas" na escola (MEC, 2015). O texto destacou:

As distinções sexistas estão presentes nas aulas, nas chamadas, nas filas, nos uniformes, no tratamento e em relação às expectativas sobre alunos ou alunas, a tolerância da violência verbal e até física entre meninos, as representações de homens e mulheres nos materiais didáticos, a abordagem quase exclusivamente biológica da sexualidade no livro didático, a estigmatização referente à manifestação da sexualidade das adolescentes, a perseguição sofrida por homossexuais, travestis e transexuais, tudo isso evidencia o quanto a escola (já) ensina, em diferentes momentos e espaços, sobre masculinidade, feminilidade, sexo, afeto, conjugalidade, família (MEC, 2015, p. 2).

As entidades chamaram atenção para a igualdade de gênero e fim das discriminações referentes à sexualidade, compromissos nos quais o Brasil é signatário. As forças políticas que apoiaram o PNE argumentavam que reduzir os contextos de desigualdades de gênero e orientação sexual nas escolas é um compromisso democrático que deve orientar a formulação de políticas.

\section{"Ideologia de gênero": uma "ameaça contra a família"}

As tensões surgidas na disputa pela (não) inclusão dos conteúdos de gênero e diversidade sexual no PNE estão condensadas em duas formulações recorrentes, estreitamente articuladas entre si: a "ideologia de gênero" seria uma considerável "ameaça contra a família". ${ }^{5}$ O Portal da Família (2013) noticiou o PNE como um "projeto contra a família", disfarçado de "combate à homofobia": "A ideologia de gênero está sendo introduzida na legislação

\footnotetext{
${ }^{5}$ Outro projeto de lei de no $6583 / 2013$, em tramitação no Congresso Nacional, trata do "Estatuto da Família", o qual reconhece a unidade familiar constituída por um homem e uma mulher em união, desconsiderando outros modelos familiares possíveis.
} 
com o objetivo de destruir o conceito tradicional da família como a união de um homem e uma mulher vivendo um compromisso de criar e educar filhos". Segundo o texto, não é dever do estado definir o melhor para as crianças "em matéria de informação sobre a sexualidade. É tarefa e direito dos próprios pais definir como esse tema será abordado e tratado nas famílias" (Portal da Família, 2013).

Para Padre Paulo Ricardo em seu blog (2014), o PNE propunha educação sexual obrigatória para crianças sem interferência dos pais, o que poderia levar a ser uma "máquina armada para a demolição e destruição da família natural" devido à "ideologia de gênero". Por sua vez, a diocese de Assis, em São Paulo, afirmou que o PNE "sem nenhuma sombra de dúvida é arbitrário, antidemocrático, antinatural". Conforme o texto, todas as diferentes confissões religiosas de fé foram confrontadas com este PNE através da "ideologia de gênero" que "deve ser rejeitada no ensino por ser uma "ditadura ideológica" (Diocese de Assis, 2014).

"Em que momento a Constituição menciona gênero?" indagou o blog católico InGuardia (2015). Segundo o texto, a carta magna não menciona esse termo, logo seria irreconhecível introduzi-lo no PNE, além de ter sido "inventado" por teóricos sociais. Tratava-se de uma "violação" do estado por meio de uma política pública sendo considerado um "estupro intelectual das nossas consciências".

O site Criacionismo reproduz um artigo de opinião de Carlos Alberto Di Franco, no qual o uso da palavra "gênero" no PNE pelas autoridades educacionais expressava uma imposição autoritária. O que se pretendia, na verdade, era o ensino "dogmático e compulsório" da "ideologia de gênero" nas escolas. O texto listava "diversos inconvenientes" para a educação tais como a perda das referências dos pais, sexualização precoce, pedofilia e "a usurpação da autoridade dos pais em matéria de educação de seus filhos," pois a "ideologia de gênero" esconderia dos pais o tipo de ensino que o filho aprende, ou seja, uma política "arbitrária" e "totalitária" (Criacionismo, 2015).

Marisa Lobo, "psicóloga cristã", filiada ao PSC-PR, avaliou em seu site ser grave o PNE conter a "ideologia de gênero". Segundo ela, a "ideologia" favorecia o ensino do "homossexualismo" às crianças. O PNE não poderia ser aprovado, pois comprometeria a instituição familiar possibilitando a "permissividade sexual" ser ensinada nas escolas (Marisa Lobo, 2014). A psicóloga é uma das mais ardorosas defensoras do combate à "ideologia de gênero", tendo protagonizado em anos anteriores a defesa do atendimento clínico psicológico para "cura gay", postura que lhe valeu a cassação de seu 
registro profissional pelo Conselho Federal de Psicologia ${ }^{6}$ Portanto, mesmo após o processo de despatologização da homossexualidade, ainda há muitos profissionais buscando a cura para homossexuais, travestis e transexuais.

Segundo Weeks (1999), a sexualidade causa incômodo desde os tempos do cristianismo pela busca por mudanças nos padrões engendrados pelas normas judaico-cristãs. O feminismo também impacta ao lutar contra a subordinação da mulher, surgindo uma crise decorrente da regulação e controle das práticas sexuais femininas. $\mathrm{O}$ ato sexual é visto pela moralidade religiosa como algo perigoso, da qual a única maneira de controlar é por meio de instituições sociais como a família, a heterossexualidade, o casamento monogâmico. Qualquer tentativa de alterar tal configuração, forças conservadoras se mobilizam para bloquear o que consideram ameaça à moralidade familiar.

Assim, os grupos religiosos e políticos que combatem a "ideologia de gênero" consideram que o PNE poderia interferir na compreensão das crianças sobre suas atribuições sociais advindas do nascimento como menina ou menino. A expressão, cunhada pelo conservadorismo religioso, está anunciada no Portal da Família (2013):

A ideologia de gênero é uma aberração de ideia imaginada por cientistas sociais que tem como eixo a afirmação de que o sexo biológico com o qual nascemos não define a nossa sexualidade. Esta é pura e simplesmente uma construção social, que pode assumir tantas variáveis quanto julgarem convenientes aqueles que querem implantar essa ideologia. O fim último dela é a completa subversão da sexualidade humana e da família natural.

Diversos interlocutores fizeram uma analogia entre a teoria social de Karl Marx e a "ideologia de gênero", associando o comunismo com a possível abolição da família (Paulo Ricardo Pe., 2014; Jornal Opção, 2015). Como expressou o padre, "a ideologia de gênero pretende destruir a família como instituição social para obter uma sociedade sem classes". O documento destacava que, segundo os teóricos do gênero, a natureza não poderia explicar as diferenças entre os homens e as mulheres, somente o contexto social e cultural.

Várias críticas dirigidas à tese da "ideologia de gênero" se voltavam para a "permissividade sexual", "libertinismo" sexual ou "perversão sexual",

\footnotetext{
${ }^{6}$ A "cura gay" está novamente em debate na Comissão de Seguridade Social e Família da Câmara dos Deputados, mediante o PL 4931/2016, de autoria do Pastor Ezequiel Teixeira (PTN-RJ), que acaba com a punição do profissional de saúde mental que tratar o paciente com "transtorno de orientação sexual".
} 
pelo fato de que ela implementaria a "sexualidade determinada pelo gênero e não pela biologia": "Não há mais sentido em sustentar a ideia de que a família é resultado da união estável entre homem e mulher" (Arquidiocese de Brasília, 2014). Como destacou o arcebispo do Rio de Janeiro, Dom Orani Tempesta (O Povo, 2014): "Em suma, nada dependeria da natureza, mas sim de uma construção sociocultural capaz de levar a relações igualitárias entre dois seres humanos, naturalmente, diferentes quanto à sexualidade". O cardeal criticou a interpretação feminista do lugar social da mulher em um sistema patriarcal, conferindo uma preferência "natural" desta pelo cuidado da casa, marido e filhos (Arquidiocese de São Sebastião, 2014). Na mesma direção, a Conferência Nacional dos Bispos do Brasil também se pronunciou preocupada com a penetração da "ideologia de gênero" nos planos de educação (CNBB, 2015).

Outro teólogo apontou a "ideologia de gênero" como "esvaziamento jurídico" do conceito de homem e de mulher, ao conferir status jurídico à chamada "identidade de gênero". Na sua acepção, os defensores desta ideologia estariam "caindo no conto do gênero" pois ela "é a pulverização da família com a finalidade do estabelecimento de um caos no qual a pessoa se torne um indivíduo solto, facilmente manipulável" (Zenit, 2014).

Em depoimento sobre o PNE, Marisa Lobo, antes citada, declarou que abordar gênero na escola seria um "abuso da liberdade de ensinar", que poderia erotizar as crianças. Assim, advertiu: "não é competência do professor ser sexólogo" (Zero Hora, 2015). Ao confundir a abordagem médica da sexualidade, derivada da sexologia como ciência constituída desde o século 19 (Russo et al., 2009), com a abordagem das ciências sociais (Weeks, 1999; Carrara et al., 2009; Louro, 1997) que a tomam como um constructo sociocultural datado historicamente e passível de elaborações diversas, a autora desconsidera a dimensão educativa mais ampla da atividade docente.

Visões deterministas baseadas no conhecimento científico advindo da biologia se opõem veementemente à perspectiva de construção social da sexualidade e do gênero nas relações humanas. Não há aceitação da diversidade sexual nem de gênero. São exatamente essas as posições em conflito no debate abordado. Segundo afirma a antropóloga colombiana Camila Esguerra, em texto publicado pelo Centro Latino-Americano em Sexualidade e Direitos Humanos (Clam, 2016a), "la ideología de género es un arma colonial". A autora ressalta: "La implantación de un sistema de sexo/género binario, heterocentrado y androcéntrico ha sido una imposición occidental, ejercida a lo largo de más de 500 años". Ou seja, uma formulação retórica para preservar um sistema que coloniza aqueles não convertidos às suas regras. 
Vários trabalhos abordam com maestria o engendramento da categoria "ideologia de gênero" (Miskolci e Campana, 2017; Carvalho e Sívori, 2017; Luna, 2017; Lowenkron e Mora, 2017) no contexto da América Latina como uma prática discursiva nascida no Vaticano, na segunda metade dos anos 90, após as Conferências Internacionais sobre População e Desenvolvimento, no Egito, em 1994 e da Mulher, ocorrida na China, em 1995. Na tentativa de deter avanços políticos, legais e institucionais na defesa dos direitos das mulheres (entre eles o aborto) e de pessoas LGBT (união civil entre pessoas do mesmo sexo), uma série de articulações políticas entre segmentos religiosos cristãos (católicos, ${ }^{7}$ evangélicos, bancadas parlamentares), ONGs (grupos pró-vida, Movimento Escola Sem Partido) ${ }^{8}$ e estado são desencadeadas nas primeiras décadas do século 21. Embora tais alianças sejam circunstanciais, o objetivo central de toda essa gramática política tem sido impedir que os direitos sexuais e reprodutivos sejam garantidos e ampliados. Miskolci e Campana (2017), Carvalho e Sívori (2017), Luna (2017) e Lowenkron e Mora (2017) ressaltam que tal empreendimento moral em torno do combate à "ideologia de gênero" se organiza disseminando "pânicos morais" na sociedade, ampliando a base de tal ativismo com segmentos não confessionais. $\mathrm{O}$ debate sobre o PNE analisado neste artigo bem retrata uma face de tal empreitada moral.

A reflexão levantada por Carrara (2015) nos ajuda a compreender em perspectiva histórica a configuração do que ele designa como "nova geografia do mal e do perigo sexual", ao discutir as políticas sexuais no Brasil e seus peculiares estilos de regulação moral. Ao analisar as transformações no dispositivo de sexualidade, constituído por uma anatomopolítica dos corpos e uma biopolítica das populações, que transita de uma sexualidade vinculada à reprodução para a sexualidade como prazer e forma de subjetivação, consolidada na noção de "direitos sexuais", o autor nos possibilita entender o deslocamento de um modo de regulação exterior ao individuo para a interioridade do sujeito, pela responsabilização e controle de si. Essa concepção individualista da sexualidade, que subsidia a noção de "direitos sexuais" vigente na modernidade ocidental, torna-se uma ameaça à ordem social e religiosa estabelecida. É exatamente essa suposta liberdade dos sujeitos se constituírem como sujeitos sexuais e de gênero que está em jogo no debate analisado. Não é ao acaso o alarde promovido em torno dos potenciais perigos

\footnotetext{
${ }^{7}$ Conforme destacam Miskolci e Campana "tal gramática se insere na ambivalência histórica do catolicismo entre uma afinidade com a esquerda em matérias econômicas e maior proximidade com a direita no que se refere à moral" (Miskolci e Campana, 2017, p. 730).

${ }^{8}$ Cf. site oficial do movimento Escola sem Partido: <escolasempartido.org>.
} 
que a inclusão das temáticas de gênero e sexualidade na educação poderiam engendrar, na medida em que implodem com modelos rígidos e "naturais" de sexualidade, gênero, casamento e família.

Como iluminam brilhantemente Vianna e Lowenkron (2017), ao tratarem das interfaces e mútuas conexões entre estado e gênero, "trata-se, antes, de um modo de regulação social e produção de diferenças e hierarquias que tem importância estratégica na constituição e na compreensão da própria forma política estatal e suas tecnologias de governo." Não abrir mão de certa forma de gestão escolar implica preservar certa governabilidade. Daí a importância do dispositivo escolar como modo de regulação sexual e social.

\section{Considerações finais}

Buscou-se compreender a configuração do debate público sobre a inclusão das categorias de gênero e sexualidade no PNE, instaurado a partir de 2011. Por meio de interlocutores em disputa, vislumbra-se o dramático contexto sociopolítico da realidade brasileira. ${ }^{9}$ De um lado, grupos religiosos de várias confissões bem representados politicamente no Congresso Nacional, de outro, segmentos minoritários da sociedade civil organizada, entidades de defesa dos direitos humanos, pesquisadores do campo alinhados ao debate contemporâneo sobre gênero, algumas autoridades governamentais empenhadas com as mudanças por meio do PNE (EBC, 2015b). A frágil representatividade política dos segmentos favoráveis ao debate sobre sexualidade e gênero nas escolas decerto comprometeu o resultado final do texto do PNE, o qual recebeu uma designação mais genérica "todas as formas de discriminação", sem especificar os conteúdos.

Gênero e sexualidade são construções sociais e culturais, mas, em geral, são tomadas por muitos como categorias "naturais". Há um padrão social imposto que constrange aqueles que não se conformam com as normas que preconizam a superioridade branca, masculina, heterossexual, e monogâmica. Há resistências para abertura do diálogo entre diferentes nos espaços sociais. $\mathrm{O}$ determinismo biológico dos corpos é reificado para fazer face às transformações corporais, sexuais e de gênero.

Os resultados mostram que para os atores institucionais contrários à inclusão dos termos gênero e orientação sexual no PNE, as desigualdades de gênero e discriminações sofridas estão em segundo plano, como o racismo e a xenofobia, ausentes no debate. A associação do pleito contido no PNE com

\footnotetext{
${ }^{9}$ Em abril de 2017, o MEC encaminhou a versão final da Base Nacional Comum Curricular ao Conselho Nacional de Educação, também com a exclusão de expressões como "identidade de gênero" e "orientação sexual" (Portal Catarinas, 2017; ONU-DH, 2017; Nova escola, 2017).
} 
um governo "de esquerda" faz o público temer os efeitos dele decorrentes, comprometendo o diálogo público devido às visões preconceituosas de certos grupos políticos religiosos.

O debate sobre gênero e sexualidade nas políticas educacionais não é novo e continua sendo objeto de disputas (Vianna e Unbehaum, 2004; Cabral, Heilborn, 2010; Vianna, 2015). É necessário ultrapassar as concepções normativas a fim de garantir a promoção da igualdade de gênero e o fim das discriminações sexuais. As influências sociais religiosas e de matrizes conservadoras são fortes intervenientes na aprovação das políticas públicas brasileiras, ressaltando as dificuldades de se afirmar o país como um estado laico. É preciso superar muitas barreiras para se afirmar os direitos humanos, garantindo assim, a democracia no Brasil.

\section{Referências}

BRASIL. Constituição da República Federativa do Brasil, 1988 <senado.gov.br/ atividade/const/con1988/con1988_12.07.2016/art_214_asp> (2 nov. 2016).

BRASIL. Estatuto da Criança e do Adolescente: lei no 8069, 13 de julho de 1990 <planalto.gov.br/ccivil_03/LEIS/L8069.htm> (2 nov. 2016).

BRASIL. Diretrizes e Bases da Educação Nacional. Lei no 9394, 20 de dezembro de 1996 < planalto.gov.br/ccivil_03/leis/L9394.htm> (02 nov. 2016).

BRASIL. Secretaria de Educação Fundamental. Parâmetros Curriculares Nacionais: introdução aos parâmetros curriculares nacionais. Brasília: MEC/SEF, 1997 <portal. mec.gov.br/seb/arquivos/pdf/livro01.pdf> (15 nov. 2016).

BRASIL. Projeto de lei $n$ o 8.035, de dezembro de 2010: aprova o Plano Nacional de Educação para o decênio 2011/2020 e dá outras providências <http://portal.mec.gov. br/index.php?option $=$ com docman $\&$ view $=$ download\&alias $=7244$-pne-projeto-leipdf\&category_slug=dezembro-2010-pdf\&Itemid=30192> (1 set. 2016).

BRASIL. Plano Nacional de Educação. Lei no 13.005, de 25 de junho de 2014 <planalto.gov.br/CCIVIL_03/_Ato2011-2014/2014/Lei/L13005.htm> (2 nov. 2016).

BRASIL. Senado Federal. Projeto de lei da Câmara no 103, 2012: aprova o Plano Nacional de Educação e dá outras providências <25.senado.leg.br/web/atividade/ materias/-/materia/108259> (2 nov. 2016).

CABRAL, Cristiane Silva; HEILBORN, Maria Luiza. Avaliação das políticas públicas sobre educação sexual e juventude: da Conferência do Cairo aos dias atuais. In: Rumos para Cairo + 20: compromissos do governo brasileiro com a plataforma da Conferência Internacional sobre População e Desenvolvimento. Brasília: Cidade Gráfica, 2010. p. 100-128.

CARRARA, Sergio; HEILBORN; Maria Luiza (orgs.). Gênero e diversidade na escola: formação de professoras/es em gênero, orientação sexual e relações étnicoraciais. Rio de Janeiro: Cepesc; Brasília: SPM, 2009. 
CARRARA, Sérgio. Moralidades, racionalidades e políticas sexuais no Brasil contemporâneo. Mana, v. 21, n. 2, p. 323-345, $2015<10.1590 / 0104-93132015$ v21n2p323>.

CARVALHO, Marcos Castro; SÍVORI, Horacio Federico. Ensino religioso, gênero e sexualidade na política educacional brasileira. Cadernos Pagu, n. 50, e175017, 2017 $<10.1590 / 18094449201700500017>$.

CELLARD, André. A análise documental. In: Jean Poupart; Jean-Pierre Deslauriers; Lionei-H. Groulx; Anne Laperriere; Robert Mayer; Álvaro Pires (orgs.). A pesquisa qualitativa: enfoques epistemológicos e metodológicos. Petrópolis: Vozes, 2008. p. 295-316.

FACCHINI, Regina; SIVORI, Horacio. Conservadorismo, direitos, moralidades e violência: situando um conjunto de reflexões a partir da Antropologia. Cadernos Pagu, n. 50, e175000, $2017<10.1590 / 18094449201700500000>$.

GESSER, Marivete; OLTRAMARI, Leandro Castro; PANISSON, Gelson. Docência e concepções de sexualidade na educação básica. Psicologia \& Sociedade, v. 27, n. 3, p. 558-568, $2015<10.1590 / 1807-03102015 v 27 n 3 p 558>$.

HEILBORN, Maria Luiza; BRANDÃO, Elaine Reis; CABRAL, Cristiane Silva. Teenage pregnancy and moral panic in Brazil. Culture, Health \& Sexuality, v. 9, n. 4 , p. 403-414, $2007<10.1080 / 13691050701369441>$.

JUNQUEIRA, Rogerio Diniz. "A homofobia não é um problema. Aqui não há gays nem lésbicas!": estratégias discursivas e estados de negação da discriminação por orientação sexual e identidade de gênero nas escolas. Revista de Psicologia da Unesp, v. 9 , n. 1, p. 123-139, 2010.

LONGARAY, Deise Azevedo; RIBEIRO, Paula Regina Costa. Espaços educativos e produção das subjetividades gays, travestis e transexuais. Revista Brasileira de Educação, v. 20, n. 62, p. 723-747, $2015<10.1590 /$ S1413-24782015206209>.

LOWENKRON, Laura; MORA, Claudia. A gênese de uma categoria. Entrevista com Rogerio Diniz Junqueira. Centro Latino-Americano em Sexualidade e Direitos Humanos: IMS/Uerj, 2017 <clam.org.br/destaque/conteudo.asp?cod=12704>

LOURO, Guacira Lopes. Gênero, sexualidade e educação: uma perspectiva pósestruturalista. São Paulo: Vozes, 1997.

LUNA, Naara. A criminalização da "ideologia de gênero": uma análise do debate sobre diversidade sexual na Câmara dos Deputados em 2015. Cadernos Pagu, n. 50, e175018, $2017<10.1590 / 18094449201700500018>$.

MARIANO, Marina; ALTMANN, Helena. Educação física na educação infantil: educando crianças ou meninos e meninas? Cadernos Pagu, n. 46, p. 411-438, 2016 $<10.1590 / 18094449201600460411>$.

MISKOLCI, Richard; CAMPANA, Maximiliano. "Ideologia de gênero": notas para a genealogia de um pânico moral contemporâneo. Sociedade e Estado, v. 32, n. 3, p. 725-747, $2017<10.1590 / \mathrm{s} 0102-69922017.3203008>$.

NARDI, Henrique Caetano; QUARTIERO, Eliana Teresinha. A diversidade sexual na escola: produção de subjetividade e políticas públicas. Revista Mal-Estar e Subjetividade, v. 11, n. 2, p. 701-725, 2011. 
OLIVEIRA, Rosana Medeiros; DINIZ, Débora. Materiais didáticos escolares e injustiça epistêmica: sobre o marco heteronormativo. Educação \& Realidade, v. 39, n. 1, p. 241-256, $2014<10.1590 / \mathrm{S} 2175-62362014000100014>$.

PALMA, Yáskara Arrial; PIASON, Aline da Silva; MANSO; Almudena Garcia Manso; STREY, Marlene Neves. Parâmetros curriculares nacionais: um estudo sobre orientação sexual, gênero e escola no Brasil. Temas em Psicologia, v. 23, n. 3, p. 727-738, $2015<10.9788 /$ TP2015.3-16>.

REIS, Toni; EGGERT, Edla. Ideologia de gênero: uma falácia construída sobre os planos de educação brasileiros. Educação \& Sociedade, v. 38, n. 138, p. 9-26, 2017 $<10.1590 /$ es0101-73302017165522>.

RUSSO, Jane A.; ROHDEN, Fabíola; TORRES, Igor; FARO, Livi. O campo da sexologia no Brasil: constituição e institucionalização. Physis, v. 19, n. 3, p. 617-636, $2009<10.1590 /$ S0103-73312009000300004>.

SÁ-SILVA, Jackson Ronie; ALMEIDA, Cristóvão Domingos; GUINDANI, Joel Felipe. Pesquisa documental: pistas teóricas e metodológicas. Revista Brasileira de História \& Ciências Sociais, v. 1, n. 1, p. 1-15, 2009.

SEFFNER, Fernando. Um bocado de sexo, pouco giz, quase nada de apagador e muitas provas: cenas escolares envolvendo questões de gênero e sexualidade. Revista de Estudos Feministas, v. 19, n. 2, p. 561-572, $2011<10.1590 / \mathrm{S} 0104-$ 026X2011000200017>.

SEFFNER, Fernando. Sigam-me os bons: apuros e aflições nos enfrentamentos ao regime da heteronormatividade no espaço escolar. Educação e Pesquisa, v. 39, n. 1, p.145-159, $2013<10.1590 /$ S1517-97022013000100010>.

VIANNA, Adriana; LOWENKRON, Laura. Apresentação. Dossiê Gênero e Estado: formas de gestão, práticas e representações. Cadernos Pagu, n. 51, e175100, 2017 $<10.1590 / 18094449201700510000>$.

VIANNA, Cláudia Pereira. O movimento LGBT e as políticas de educação de gênero e diversidade sexual: perdas, ganhos e desafios. Educação e Pesquisa, v. 41, n. 3, p. 791-806, $2015<10.1590 / \mathrm{s} 1517-97022015031914>$.

VIANNA, Claudia Pereira; CARREIRA, Denise; LEÃO, Ingrid; UNBEHAUM; Sandra; CARNEIRO, Suelani; CAVASIN; Sylvia. Gênero e educação: fortalecendo uma agenda para as políticas educacionais. São Paulo: Ação Educativa, Cladem, Ecos, Geledés, Fundação Carlos Chagas, 2016.

VIANNA, Claudia Pereira; UNBEHAUM, Sandra. O gênero nas políticas públicas de educação no Brasil: 1988-2002. Cadernos de Pesquisa, v. 34, n. 121, p. 77-104, 2004 $<10.1590 /$ S0100-15742004000100005>.

WEEKS, Jefrey. O corpo e a sexualidade. In: Guacira Lopes Louro (org.). O corpo educado: pedagogias da sexualidade. Belo horizonte: Autêntica, 1999. p. 35-82. 


\section{ANEXo}

\section{Documentos selecionados para análise}

AGENCIA Brasil. Unesco defende que educação em sexualidade e gênero seja prevista em lei, 08/06/16 <agenciabrasil.ebc.com.br/educacao/noticia/2016-06/ unesco-defende-que-educacao-em-sexualidade-e-genero-esteja-prevista-em-lei> (2 nov. 2016).

ARQUIDIOCESE de Brasília. Câmara Federal vota PNE que inclui ideologia de gênero, 18/03/2014 <arquidiocesedebrasilia.org.br/noticias.php?cod=1700> (12 nov. 2016).

ARQUIDIOCESE de São Sebastião. Reflexões sobre a "ideologia de gênero", 25/03/2014 <arqrio.org/formacao/detalhes/386/reflexoes-sobre-a-ideologia-degenero $>$ (12 nov. 2016).

ASSOCIAÇÃO Brasileira de Antropologia. Nota sobre a supressão de "gênero" e "orientação sexual" nos planos municipais, estaduais e nacional de educação, 18/06/2015 < http://portal.abant.org.br/images/Noticias/Oficio_n\%C2\%BA_028_Nota_sobre_a_supress $\% \mathrm{C} 3 \% \mathrm{~A} 30$ de g $\% \mathrm{C} 3 \% \mathrm{AAnero}$ e_orienta $\% \mathrm{C} 3 \% \mathrm{~A} \overline{7} \% \mathrm{C} \overline{3} \%$ A3o_sexual_nos_planos_municipais_estaduais_e_nacional_de_educa $\% \mathrm{C} 3 \% \mathrm{~A} 7 \%$ C3\%A3o.pdf $>$ (2 nov. 2016).

ASSOCIAÇÃO Brasileira de Ciência Política. Carta Pública da Associação Brasileira de Ciência Política contra a eliminação de diretrizes para a igualdade de gênero e o respeito à diversidade sexual dos planos de educação, 25/06/2015<cienciapolitica.org. br/carta-publica-da-associacao-brasileira-de-ciencia-politica-contra-a-eliminacao-dediretrizes-para-a-igualdade-de-genero-e-o-respeito-a-diversidade-sexual-dos-planosde-educacao/\#.VYx4cVyvPKC> (2 nov. 2016).

ASSOCIAÇÃO Nacional de Pós-Graduação e Pesquisa Em Educação. Nota Pública sobre a importância da abordagem de gênero e sexualidades na Educação, 22/05/2016 $<$ anped.org.br/sites/default/files/resources/Carta_P_blica_GT_23_22_06_15.pdf> (2 nov. 2016).

CENTRO Latino-Americano em Sexualidade e Direitos Humanos. Educação: para onde vamos? 16/06/2016b <clam.org.br/noticias-clam/conteudo.asp? cod=12394> (10 ago. 2017).

CENTRO Latino-Americano em Sexualidade e Direitos Humanos. Fazer e desfazer a ideologia de gênero, 19/12/2016 <http://clam.org.br/destaque/conteudo. asp? cod=12589> (10 ago. 2017).

CONFERÊNCIA Nacional dos Bispos do Brasil. CNBB divulga nota sobre a ideologia de gênero nos planos de educação, 18/06/2015<https://jovensconectados.org.br/cnbbdivulga-nota-sobre-inclusao-da-ideologia-de-genero-nos-planos-de-educacao.html > (2 nov. 2016).

CONGRESSO em foco. Unesco: Brasil é reprovado no quesito igualdade de gênero nas escolas, 23/11/2015a <congressoemfoco.uol.com.br/noticias/unesco-brasil-ereprovado-no-quesito-igualdade-de-genero-nas-escolas/> (2 nov. 2016). 
CONGRESSO em foco. A "ideologia de gênero", o respeito e os planos de educação, 24/06/2015b <congressoemfoco.uol.com.br/opiniao/colunistas/a-\%E2\% $80 \% 9$ Cideologia-de-genero $\%$ E2\%80\%9D-o-respeito-e-os-planos-de-educacao/> (2 nov. 2016).

CONSELHO Nacional de Educação. Nota Pública Às Assembleias Legislativas, à Câmara Legislativa do DF, às Câmaras de Vereadores, aos Conselhos Estaduais, Distrital e Municipais de Educação e à Sociedade Brasileira, 1\%/9/2015<http://www. spm.gov.br/noticias/conselho-nacional-de-educacao-emite-nota-sobre-ideologia-degenero-nos-planos-de-educacao/nota_publica_sobre_ideologia_genero_01_09-1.pdf> (2 nov. 2016).

CRIACIONISMO. Educação sexual compulsória e ideologia de gênero, 11/06/2015 <criacionismo.com.br/2015/06/educacao-sexual-compulsoria-e-ideologia.html> (2 nov. 2016).

DE OLHO nos Planos. Plano Nacional de Educação sofre pressão de grupos religiosos e pode deixar de promover igualdade de gênero, 10/04/2014<deolhonosplanos.org. br/plano-nacional-de-educacao-sofre-pressao-de-grupos-religiosos-e-pode-deixar-depromover-igualdade-de-genero/> (12 nov. 2016).

DE OLHO nos Planos. Nota Pública em defesa da igualdade de gênero nos Planos de Educação e de uma educação laica e democrática, 06/06/2015<deolhonosplanos.org.br/ wp-content/uploads/2015/06/Nota-em-defesa-da-igualdade-de-g\%C3\%AAneronosplanos-de-educa\%C3\%A7\%C3\%A3o_FINAL1.pdf> (2 nov. 2016).

DIOCESE de Assis. O Plano Nacional de Educação e a ideologia de gênero, 18/03/2014 <http://diocesedeassis.org/portal/index.php/noticias/diocesanas/752-oplano-nacional-da-educacao-pne-e-a-ideologia-de-genero> (12 nov. 2016).

EDUCAR para crescer. Por que a escola deve combater a desigualdade de gênero, 01/09/2014 <educarparacrescer.abril.com.br/comportamento/combater-desigualdadegenero-798533.shtml> (2 nov. 2016).

EL PAÍS. Católicos e evangélicos em cruzada contra a palavra gênero na educação, 11/06/2015 < brasil.elpais.com/brasil/2015/06/11/politica/1434059650_940148.html> (12 nov. 2016).

EMPRESA Brasil de Comunicação. Igualdade de gênero nos planos pode diminuir desigualdades, defende ABGLT, 29/07/2015a <ebc.com.br/educacao/2015/07/igualdadede-genero-nos-planos-pretende-diminuir-desigualdades-e-inferiorizacao-de> (2 nov. 2016).

EMPRESA Brasil de Comunicação. Janine critica retirada da questão de gênero de planos de educação, 08/07/2015b <ebc.com.br/educacao/2015/07/janine-criticaretirada-da-questao-de-genero-de-planos-de-educacao> (2 nov. 2016).

GAZETA do Povo. Polêmica sobre questão de gênero predomina em reunião sobre PNE, 19/03/2014 <gazetadopovo.com.br/educacao/polemica-sobre-questao-de-generopredomina-em-reuniao-sobre-pne-1yjh89jvjvwkitv6xd2n6e53i> (12 nov. 2016).

GELEDÉS Instituto da Mulher Negra. Segundo pesquisador, muitos pontos sobre sexualidade estão ausentes do Plano Nacional de Educação, 03/08/2011 <geledes.org. br/segundo-pesquisador-muitos-pontos-sobre-sexualidade-estao-ausentes-do-planonacional-de-educacao/\#gs.T33MIpE> (12 nov. 2016). 
GELEDÉS Instituto da Mulher Negra. É preciso aperfeiçoar o relatório do PNE, 01/04/2014 <geledes.org.br/carta-aberta-e-preciso-aperfeicoar-o-relatorio-dopne/\#gs.bR76BgM> (16 dez. 2016).

GELEDÉS Instituto da Mulher Negra. Sobre o que chamam "ideologia de gênero", 27/09/2015 <geledes.org.br/sobre-o-que-chamam-ideologia-de-genero/\#gs.ugirQrE> (2 nov. 2016)

GOSPEL +. Marisa Lobo alerta sobre "ideologia de gênero" no Plano Nacional de Educação, 22/04/2014 <noticias.gospelmais.com.br/marisa-lobo-alerta-ideologiagenero-plano-nacional-educacao-67075.html> (2 nov. 2016).

INGUARDIA. PNE e a ideologia de gênero, 14/08/2015 <inguardia.blogspot.com. br/2015/08/pne-e-ideologia-de-genero.html> (2 nov. 2016).

JORNAL Opção. Planos de educação querem experimentar a ideologia de gênero nesta geração, 14/06/2015<jornalopcao.com.br/colunas-e-blogs/imprensa/planosde-educacao-querem-experimentar-a-ideologia-de-genero-nesta-geracao-decriancas-38069/> (12 nov. 2016).

MARISA Lobo Ministério. Ideologia de gênero neutro mostra que não deu certo, 28/08/2014<marisalobo.com.br/ideologia-de-genero-neutro-mostra-que-nao-deucerto $>$ (2 nov. 2016).

MINISTÉRIO da Educação. Nota Técnica no 24/2015, 17/08/2015 <spm.gov.br/ assuntos/conselho/nota-tecnica-no-24-conceito-genero-no-pne-mec.pdf> (2 nov. 2016).

NOVA Escola. Os termos "gênero" e "orientação sexual" têm sido retirados dos documentos oficiais sobre Educação no Brasil. Por que isso é ruim? 11/04/2017 $<$ novaescola.org.br/conteudo/4900/os-termos-genero-e-orientacao-sexual-tem-sidoretirados-dos-documentos-oficiais-sobre-educacao-no-brasil-por-que-isso-e-ruim> (10 ago. 2017).

O POVO. Dom Orani alerta sobre o perigo da ideologia de gênero, 25/03/2014 $<$ blog.opovo.com.br/ancoradouro/dom-orani-lanca-nota-alertando-sobre-perigo-daideologia-genero-pne/> (12 nov. 2016).

O POVO. Perigo: Governo do PT planeja introduzir ideologia de gênero nas escolas através do Plano Nacional de Educação, 9/12/2013<blog.opovo.com.br/ancoradouro/ perigo-governo-pt-planeja-introduzir-ideologia-de-genero-nas-escolas-atraves-planonacional-de-educacao> (12 nov. 2016).

ONU Alto Comissariado de Direitos Humanos. Carta ao estado brasileiro, 13 abril 2017 <ohchr.org/Documents/Issues/Opinion/Legislation/OLBrazileducation.pdf> (10 ago. 2017).

ONU Mulheres. Nota pública sobre a garantia da educação sobre gênero na educação brasileira, 5/5/2016 < onumulheres.org.br/noticias/nota-publica-da-onu-mulheresbrasil-sobre-a-garantia-da-educacao-sobre-genero-na-educacao-brasileira/> (2 nov. 2016).

ONU Mulheres. "É preciso falar sobre gênero nas escolas", diz cientista social Sylvia Cavasin, 8/4/2017<onumulheres.org.br/noticias/e-preciso-falar-de-genero-nasescolas-diz-cientista-social-sylvia-cavasin/> (10 ago. 2017). 
OUTRAS Palavras. Educação, o novo alvo do fundamentalismo, 7/4/2014< < outras palavras.net/brasil/educacao-o-novo-alvo-do-fundamentalismo/> (19 dez. 2016).

PADRE Paulo Ricardo. Urgente: Congresso pode aprovar a ideologia de gênero como meta da educação, 10/03/2014. < padrepauloricardo.org/blog/urgente-congresso-podeaprovar-a-ideologia-de-genero-como-meta-da-educacao > (12 nov 2016).

PORTAL Aprendiz. Professor que discutir gênero na escola poderá ser preso, 12/11/15 <portal.aprendiz.uol.com.br/2015/11/12/professor-que-discutir-genero-na-escolapodera-ser-preso/> (2 nov. 2016).

PORTAL Catarinas. OAB: "supressão de 'orientação sexual' e 'identidade de gênero' é nefasto retrocesso", 17/4/2017 <catarinas.info/oab-supressao-de-orientacao-sexuale-identidade-de-genero-e-nefasto-retrocesso/> (10 ago. 2017).

PORTAL da Família. Projetos contra a família: PLC 122, Plano Nacional de Educação e a ameaça de gênero, 15/12/2013 < portaldafamilia.org/artigos/PLC122-PNE.shtml> (3 nov. 2016).

PORTAL IG. Exclusão de Gênero do Plano Nacional de Educação é retrocesso, diz educador, 26/12/15<ultimosegundo.ig.com.br/educacao/2015-12-26/exclusao-de-generodo-plano-nacional-de-educacao-e-retrocesso-diz-educador.html > (2 nov. 2016).

PRAGMATISMO Político. Conservadores conseguem vitória em texto do PNE, 29/6/2015 <pragmatismopolitico.com.br/2014/04/conservadores-conseguem-vitoriaem-texto-pne.html> (2 nov. 2016).

REVOLTA Brasil. Kit gay volta com força total, são bolsas para gays, cotas para gays e ensino de sexualidade a partir dos 6 anos de idade nas escolas, 25/04/2014 $<$ revoltabrasil.com.br/midia/3344-kit-gay-volta-com-forca-total-sao-bolsas-paragays-cotas-para-gays-e-ensino-de-sexualidade-a-partir-dos-6-anos-de-idade-nasescolas.html> (2 nov. 2016).

WILKINSON, Annie. Latin America's Gender Ideology Explosion, 28 Mar 2017 $<$ sxpolitics.org/latin-americas-gender-ideology-explosion/16724> (10 ago. 2017).

ZENIT. Caindo no conto do gênero, 04/04/2014 < pt.zenit.org/articles/caindo-noconto-do-genero/> (12 nov. 2016).

ZERO HORA. Pelo menos oito Estados retiram referências a gênero dos planos de educação, 29/06/2015 <zh.clicrbs.com.br/rs/vida-e-estilo/educacao/ noticia/2015/06/pelo-menos-oito-estados-retiram-referencias-a-genero-dos-planosde-educacao-4791753.html> (2 nov. 2016).

Recebido em: 29 ago. 2017

Aprovado em: 27 fev. 2018

Autora correspondente:

Elaine Reis Brandão

Instituto de Estudos em Saúde Coletiva

Universidade Federal do Rio de Janeiro (UFRJ)

Av. Horácio Macedo, s/n., Praça da Prefeitura Universitária

Ilha do Fundão - Cidade Universitária

21941-598 Rio de Janeiro, RJ, Brasil 